\title{
Practices and Obstacles to Provider-Initiated HIV Testing and Counseling (PITC) Among Healthcare Providers in Côte d'Ivoire
}

\author{
Maxime Inghels ${ }^{1,2}$ (1) $\cdot$ Arsène Kra Kouassi ${ }^{3} \cdot$ Serge Niangoran $^{3} \cdot$ Anne Bekelynck $^{2,3} \cdot$ Séverine Carillon $^{2} \cdot$ Lazare Sika $^{4}$. \\ Christine Danel $^{3,5} \cdot$ Mariatou Kone $^{6}$. Annabel Desgrees du Lou ${ }^{2} \cdot$ Joseph Larmarange $^{2} \cdot$ for the ANRS 12323 DOD-CI \\ Study Group
}

Published online: 24 May 2020

(c) The Author(s) 2020

\begin{abstract}
Practices of Provider-Initiated HIV Testing and Counseling (PITC) remains suboptimal in Côte d'Ivoire. The aim of this survey was to identify the practices and obstacles to PITC among healthcare professionals in Côte d'Ivoire. A nationally representative cross-sectional survey was conducted in 2018 by telephone among three separate samples of midwives, nurses and physicians practicing in Côte d'Ivoire. The number of HIV tests proposed during consultation in the month preceding the survey was collected for each professional. Factors associated with the number of proposed tests were identified through ordinal logistic regression models. A total of 298 midwives, 308 nurses and 289 physicians were interviewed. Midwives proposed the test more frequently, followed by nurses and physicians. Among midwives, a higher number of proposed tests was associated with the perception that HIV testing does not require specific consent compared to other diseases (aOR 4.00 [95\% CI 1.37-14.29]). Among nurses, having received HIV training and the presence of community HIV counselors were associated with a higher number of proposed tests (aOR 2.01 [1.31-3.09] and aOR 1.75 [1.14-2.70], respectively). For physicians, the presence of a voluntary testing center was associated with a higher number of proposed tests (aOR 1.69 [1.01-2.86]). PITC practices and barriers differed across professions. Beyond improving environmental opportunities such as dedicated staff or services, strengthening the motivations and capabilities of healthcare professionals to propose testing could improve PITC coverage.
\end{abstract}

Keywords Provider initiated testing and counselling $\cdot$ HIV testing $\cdot$ Côte d'Ivoire $\cdot$ Health personnel $\cdot$ Phone-based survey

\section{Resumen}

Las prácticas de Asesoramiento y Pruebas de VIH Iniciadas por el Proveedor (APIP) siguen siendo subóptimas en Côte d'Ivoire. El objetivo de este estudio fue identificar las prácticas y los obstáculos a las APIP entre los profesionales de la salud en Côte d'Ivoire. En 2018 se llevó a cabo una encuesta transversal representativa a nivel nacional por teléfono entre

The members of the ANRS 12323 DOD-CI Study Group are listed in the Acknowledgment section.

Electronic supplementary material The online version of this article (https://doi.org/10.1007/s10461-020-02923-0) contains supplementary material, which is available to authorized users.

Maxime Inghels

maxime.inghels@gmail.com

1 Lincoln International Institute for Rural Health (LIIRH), University of Lincoln, Brayford Pool, Lincoln, Lincolnshire LN6 7TS, UK

2 Centre Population et Développement (UMR 196 Paris Descartes - IRD), SageSud (ERL INSERM 1244), Institut de Recherche Pour Le Développement, Paris, France
3 Programme PAC-CI/ANRS, Centre Hospitalier Universitaire de Treichville, Abidjan, Ivory Coast

4 École Nationale Supérieure de Statistique et d'Economie Appliquée (ENSEA), Abidjan, Ivory Coast

5 Centre Inserm 1219, Université de Bordeaux, Bordeaux, France

6 Institut D'Ethno-Sociologie (IES), Abidjan, Ivory Coast 
tres muestras separadas de parteras, enfermeras y médicos que ejercen en Côte d'Ivoire. Se recogió para cada profesional el número de pruebas de VIH propuestas durante la consulta en el mes anterior a la encuesta. Los factores asociados con el número de pruebas propuestas se identificaron mediante modelos ordinales de regresión logística. Se entrevistó a un total de 298 parteras, 308 enfermeras y 289 médicos. Las parteras propusieron la prueba con mayor frecuencia, seguidas de las enfermeras y los médicos. Entre las parteras, un mayor número de pruebas propuestas se asoció a la percepción de que la prueba del VIH no requiere un consentimiento específico en comparación con otras enfermedades (aOR 4,00 [IC del 95\%: 1,37-14,29]). Entre las enfermeras, el haber recibido capacitación sobre el VIH y la presencia de consejeros comunitarios sobre el VIH se asociaron con un mayor número de pruebas propuestas (aOR 2,01 [1,31-3,09] y aOR 1,75 [1,14-2,70], respectivamente). Para los médicos, la presencia de un centro de pruebas voluntarias se asoció con un mayor número de pruebas propuestas (aOR 1,69 [1,01-2,86]). Las prácticas y barreras del APIP difieren entre las profesiones. Más allá de mejorar las oportunidades del entorno, como el personal o los servicios dedicados, el fortalecimiento de las motivaciones y capacidades de los profesionales de la salud para proponer pruebas podría mejorar la cobertura del APIP.

\section{Background}

Because of the limitations of voluntary HIV testing (patientinitiated testing) and the insufficient coverage of HIV testing, the World Health Organization has recommended ProviderInitiated HIV Testing and Counseling (PITC) since 2007 [1]. PITC adoption in the majority of sub-Saharan countries has contributed significantly to the increase in HIV testing coverage [2-4]. Despite its systematic recommendation to certain audiences (e.g., pregnant women) or in certain epidemiological contexts (i.e., areas with HIV prevalence above $1 \%$ ), routine PITC implementation has remained suboptimal in sub-Saharan Africa [5]. Test proposal rates in recommended situations by a healthcare professional vary between 24 and $94 \%$ across studies [5].

Some studies have highlighted barriers faced by healthcare professionals in their PITC practice. At the individual level, poor perception of the PITC [6], lack of motivation [7-10] and difficulties in offering testing or counseling [8-12] are mentioned, as are the workload associated with PITC $[8,11,13]$ and the lack of specific training $[9,11$, 14-17]. At the structural level, a lack of trained staff [7, 8, $12,14]$, shortages of testing kits $[10,11,13,16]$ and inadequate space that does not guarantee confidentiality [7-14] are associated with low PITC practice. Some studies have suggested that PITC organization (i.e., professionals performing the different steps of testing, patient referrals or no referrals for testing) can facilitate test proposal $[15,18,19]$.

Since 2009, routine PITC has been recommended in Côte d'Ivoire to all patients, regardless of their reason for consultation [20]. Nevertheless, the proposal rates observed in consultation remain low. According to 2017 national data, only $15.2 \%$ of $12,955,898$ consultations conducted nationally were documented with a test proposal, and $75.9 \%$ of these proposals resulted in HIV testing [21]. These figures were consistent with another study that also found a test proposal rate of approximately $20 \%$ in outpatient services [22]. In a country where the HIV prevalence was $2.8 \%$ in 2017 and where only 54\% of people living with HIV knew their status, it crucial to understand, from the perspective of healthcare professionals, what factors influence testing proposal practices [23, 24].

To our knowledge, no studies have documented the obstacles to the practice of PITC at the national level in Côte d'Ivoire. The objective of this analysis is therefore to describe PITC practices by healthcare professionals and to identify factors associated with this practice.

\section{Methods}

A cross-sectional survey was conducted between February and November 2018 by telephone among midwives, nurses and physicians throughout Côte d'Ivoire. Lists of telephone contacts were obtained from the Ministry of Health for nurses and midwives and from the Ivorian Medical Association for physicians. A random sample (equal probabilities) was selected from each list. In the case of phone contact, the survey was presented, and informed consent was orally obtained. In the absence of contact, each telephone number was dialed up to 15 times consecutively without contact before being considered unreachable.

Healthcare professionals were asked about the number of HIV tests they proposed in consultation during the previous month (none, between 1 and 5, between 6 and 10, between 11 and 20, and 21 or more). Other collected data concerned healthcare professionals' characteristics, their professional training and the characteristics of their main facility (i.e., the one in which they practiced most often). Potential factors were classified according to three dimensions directly inspired by the conceptual model of work performance [25]: motivation, capability and opportunity (Fig. 1).

According to this model, motivation is defined as the desire and willingness of professionals to act. In our survey, motivation included the perceived usefulness of a systematic proposal of an HIV test to any patient, the belief that offering an HIV test requires specific consent compared to other tests and a relative living with HIV. 
Fig. 1 Measured factors with practice and obstacles to provider-initiated HIV testing and counseling according to the Motivation-OpportunityCapability framework, adapted from Boudreau et al. [24]

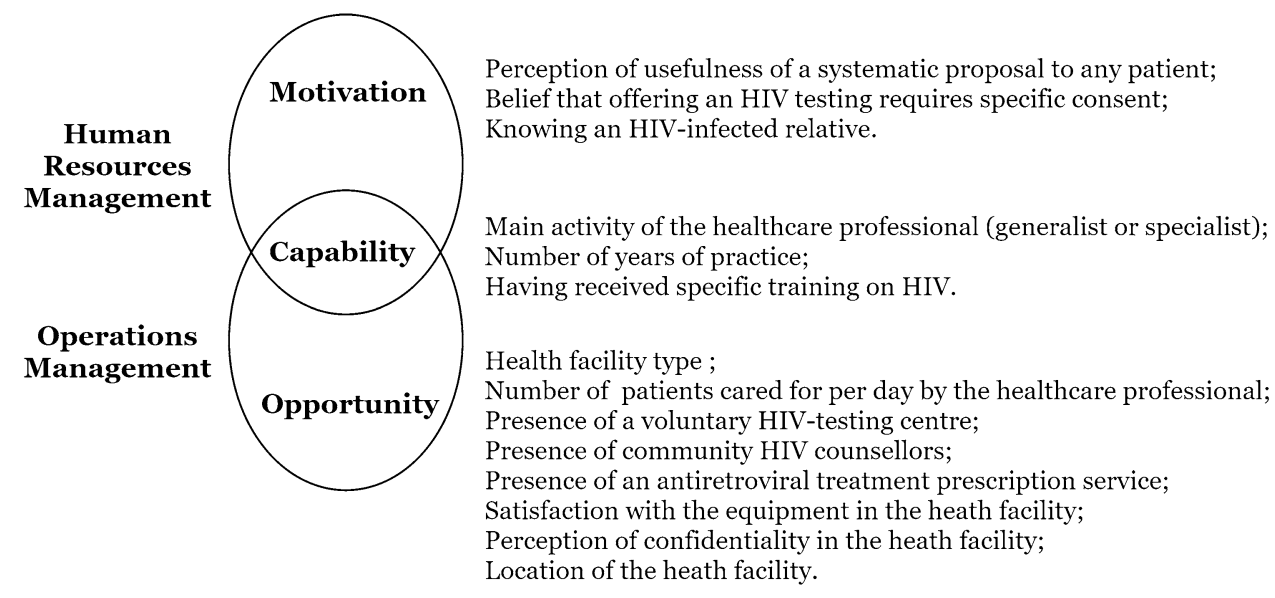

Capabilities are defined as the skills, knowledge and abilities necessary to carry out an action in line with the objectives of the health structure. This concept can be applied both at the level of the healthcare professional and at the level of his/her facility. In our survey, we measured the main activity of the healthcare professional (general practitioner or specialist, with all midwives considered specialists), the number of years of practice and having received specific training on HIV.

Opportunity refers to situations encountered within the institution that facilitate the execution of actions and their expected effects. In our survey, opportunity included the type of health facility (hospital, health center, private or other) and, within this facility, the number of patients seen per day by the surveyed healthcare professional and the presence of a voluntary HIV testing center, community HIV counselors, and/or an antiretroviral treatment (ARV) prescription service. In addition, satisfaction with the available equipment, the perception of confidentiality in the facility and its location (Abidjan, urban or rural departments) were collected.

The analyses were stratified by profession (midwife, nurse and physician). Bivariate analyses were conducted to describe associations with the number of proposed tests in the month preceding the survey. Fisher's exact tests were used to calculate the corresponding $\mathrm{p}$-values. The significant variables at the 0.20 threshold in the bivariate analyses were included in multivariate ordinal logistic regression models. The ordinal categories of the number of proposed tests in the preceding month were none, between 1 and 5, between 6 and 10, between 11 and 20, and 21 or more. A step-by-step downward selection using the Akaike information criterion was performed to obtain the final models. Likelihood ratio tests were used to calculate the global p-values in these models. We used R (version 3.3.5) and the ordinal package [26].

\section{Results}

\section{Sample description}

Overall, 1450 telephone numbers were called (425 midwives, 425 nurses, 600 physicians). After excluding off-target numbers, 1329 healthcare professionals were eligible for the survey. The participation rates (taking into account refusal rates and execution failures) were $75.8 \%, 83.3 \%$ and $58.3 \%$ for midwives, nurses and physicians, respectively (Table S1, Supplemental Digital Content-SDC).

A total of 299 midwives, 313 nurses and 316 physicians were interviewed. Among them, 1 midwife, 5 nurses and 27 physicians reported positions in which they were not in contact with patients (e.g., administration, management, expertise); thus, they were excluded from our analyses.

Among all healthcare professionals, 93.6\% mentioned the availability of an HIV-testing service within their facility. However, only two-thirds mentioned the presence of a Voluntary HIV Testing Center (VTC) (Table 1). The presence of an ARV prescription service was mentioned by two-thirds of health professionals.

Although almost all healthcare professionals were in contact with HIV-infected patients (96.4\%), 53.3\%, 67.8\% and $77.1 \%$ of midwives, nurses and physicians, respectively, had a relative living with HIV (Table 1). Almost all healthcare professionals reported that HIV testing required specific consent compared to other diseases.

Nurses were the healthcare professional group who reported having been trained for HIV the least often (50.3\% vs. $58.4 \%$ and $63.3 \%$ for midwives and physicians, respectively).

The median number of patients seen per day in consultation by health professionals was 15 (interquartile range 10-20). 
Table 1 Description of curricula, professional activity and professional structure among midwives, nurses and physicians, Côte d'Ivoire, DOD-CI study, $2018(\mathrm{n}=895)$

\begin{tabular}{|c|c|c|c|c|c|c|}
\hline & \multicolumn{2}{|c|}{ Midwives $(\mathrm{n}=298)$} & \multicolumn{2}{|c|}{ Nurses $(n=308)$} & \multicolumn{2}{|c|}{$\begin{array}{l}\text { Physicians } \\
(\mathrm{n}=289)\end{array}$} \\
\hline & $\mathrm{N}$ & $\%$ & $\mathrm{~N}$ & $\%$ & $\mathrm{~N}$ & $\%$ \\
\hline \multicolumn{7}{|c|}{ Education and professional experience } \\
\hline \multicolumn{7}{|c|}{ Main activity } \\
\hline Generalist & 0 & 0.0 & 162 & 52.6 & 176 & 60.9 \\
\hline Specialist $^{\mathrm{a}}$ & 298 & 100.0 & 146 & 47.4 & 113 & 39.1 \\
\hline \multicolumn{7}{|c|}{ Years of professional practice } \\
\hline$\leq 3$ years & 211 & 70.8 & 184 & 59.7 & 74 & 25.6 \\
\hline$\geq 4$ years & 87 & 29.2 & 124 & 40.3 & 215 & 74.4 \\
\hline \multicolumn{7}{|c|}{ Has already received specific training on HIV } \\
\hline Yes & 174 & 58.4 & 155 & 50.3 & 183 & 63.3 \\
\hline No & 124 & 41.6 & 153 & 49.7 & 106 & 36.7 \\
\hline
\end{tabular}

Activities and services within the structure

Average number of patients cared for by the healthcare professional per day

$\begin{array}{llclccc}\leq 9 & 66 & 22.1 & 70 & 22.7 & 49 & 17.0 \\ 10-19 & 130 & 43.6 & 111 & 36.0 & 138 & 47.8 \\ \geq 20 & 102 & 34.2 & 127 & 41.2 & 102 & 35.3 \\ \begin{array}{l}\text { Type of health facility } \\ \text { Hospital }\end{array} & 141 & 47.3 & 175 & 56.8 & 146 & 50.5 \\ \text { Health center } & 143 & 48.0 & 111 & 36.0 & 47 & 16.3 \\ \text { Medical office or clinic } & 2 & 0.7 & 3 & 1.0 & 54 & 18.7 \\ \text { Other structure } & 12 & 4.0 & 19 & 6.2 & 42 & 14.5\end{array}$

Presence of a voluntary HIV-testing center

$\begin{array}{llccccl}\text { Yes } & 193 & 65.6 & 178 & 62.9 & 180 & 69 \\ \text { No } & 89 & 30.3 & 93 & 32.9 & 69 & 26.4 \\ \text { Don't know } & 12 & 4.1 & 12 & 4.2 & 12 & 4.6\end{array}$

Presence of community HIV counselors

$\begin{array}{llccccc}\text { Yes } & 127 & 42.6 & 121 & 39.3 & 100 & 34.6 \\ \text { No } & 149 & 50.0 & 173 & 56.2 & 167 & 57.8 \\ \text { Don't know } & 22 & 7.4 & 14 & 4.5 & 22 & 7.6\end{array}$

Presence of an ARV prescription service

$\begin{array}{lllllll}\text { Yes } & 193 & 65.6 & 178 & 62.9 & 180 & 69.0 \\ \text { No } & 89 & 30.3 & 93 & 32.9 & 69 & 26.4 \\ \text { Don't know } & 12 & 4.1 & 12 & 4.2 & 12 & 4.6\end{array}$

Satisfaction with available equipment and premises

$\begin{array}{llcllll}\text { Very poorly/poorly equipped } & 147 & 49.3 & 174 & 56.5 & 117 & 40.4 \\ \begin{array}{l}\text { Very good/well equipped } \\ \text { Opinion regarding confidentiality }\end{array} & 151 & 50.7 & 134 & 43.5 & 141 & 59.5 \\ \begin{array}{l}\text { Confidentiality guaranteed } \\ \text { Confidentiality not guaranteed }\end{array} & 294 & 98.7 & 296 & 96.1 & 271 & 93.8 \\ \text { Don't know } & 4 & 1.3 & 9 & 2.9 & 16 & 5.5 \\ \text { Department } & 0 & 0.0 & 3 & 1.0 & 2 & 0.7 \\ \text { Abidjan } & & & & & & \\ \text { Urban departments } & 83 & 27.9 & 70 & 22.7 & 183 & 63.3 \\ \text { Rural departments } & 58 & 19.5 & 68 & 22.1 & 37 & 12.8 \\ \text { Opinons and perceptions } & 157 & 52.7 & 170 & 55.2 & 69 & 23.9\end{array}$

Opinions and perceptions

Belief that offering HIV testing systematically to any patient in medical consultation is

\begin{tabular}{lllllll} 
Very useful & 138 & 46.3 & 135 & 43.8 & 87 & 30.1 \\
Useful & 154 & 51.7 & 146 & 47.4 & 154 & 53.3 \\
No opinion & 3 & 1.0 & 10 & 3.2 & 6 & 2.1 \\
Useless & 3 & 1.0 & 17 & 5.5 & 42 & 14.5 \\
\hline
\end{tabular}


Table 1 (continued)

\begin{tabular}{|c|c|c|c|c|c|c|}
\hline & \multicolumn{2}{|c|}{ Midwives $(\mathrm{n}=298)$} & \multicolumn{2}{|c|}{ Nurses $(n=308)$} & \multicolumn{2}{|c|}{$\begin{array}{l}\text { Physicians } \\
(\mathrm{n}=289)\end{array}$} \\
\hline & $\mathrm{N}$ & $\%$ & $\mathrm{~N}$ & $\%$ & $\mathrm{~N}$ & $\%$ \\
\hline \multicolumn{7}{|c|}{ Belief that HIV testing requires more caution in obtaining consent than other tests } \\
\hline Yes & 275 & 92.3 & 289 & 93.8 & 249 & 86.2 \\
\hline No & 22 & 7.4 & 17 & 5.5 & 40 & 13.8 \\
\hline Don't know & 1 & 0.3 & 2 & 0.6 & 0 & 0.0 \\
\hline \multicolumn{7}{|c|}{ Knows an HIV-infected relative (excluding patients) } \\
\hline Yes & 159 & 53.4 & 209 & 67.9 & 223 & 77.2 \\
\hline No & 139 & 46.6 & 99 & 32.1 & 66 & 22.8 \\
\hline
\end{tabular}

${ }^{a}$ Specialized adult, prenatal, postnatal and family planning, pediatric, hospitalization and other consultations

\section{Number of Proposed Tests and Associated Factors}

The number of proposed tests in the previous month differed by the medical profession (Fig. 2). Midwives reported a higher number of tests compared to nurses and physicians: $58.4 \%$ had proposed 21 tests or more in the previous month compared to $30.8 \%$ and $26.6 \%$ for nurses and physicians, respectively. The proportion of professionals who did not propose testing was higher among physicians (32.9\% vs. $21.43 \%$ and $13.8 \%$ among nurses and midwives, respectively).

In the bivariate analyses, there were different dimensions associated with the number of proposed tests according to professional position (Fig. 3; the corresponding data are presented in Table S2, SDC). Regarding motivation and capabilities, only knowing a relative living with HIV and having received HIV training were significantly associated with the number of tests proposed among nurses (exact F-test: $p=0.051$ and $p<0.001$ respectively). Regarding opportunities, the type of health facility was associated with the number of proposed tests regardless of the profession (the number of proposed tests was higher in health centers than in hospitals and other medical structures; exact F-test: $\mathrm{p}<0.001, \mathrm{p}=0.009$ and $\mathrm{p}=0.007$ among midwives, nurses and physicians respectively). The availability of a VTC, community HIV counselors and/or an ARV prescription service were significantly associated with a greater number of proposed tests for physicians and nurses.

In the multivariate ordinal regression models, factors related to motivation (opinion on the collection of consent for HIV testing) and opportunities (type of health facility and presence of an ARV prescription service in this facility) were significantly associated with the number of proposed tests for midwives (Fig. 4). Among midwives, the belief that more caution is needed to obtain consent for HIV testing than for other diseases was associated with a lower number of proposed tests (aOR 0.25 [95\% confidence interval 0.07-0.73], $\mathrm{p}=0.010$ ) (Table S3, SDC).

Among nurses, factors related to capabilities (having received specific training on HIV) and opportunities (type of health facility, presence of community HIV counselors, availability of an ARV prescription service and geographical
Fig. 2 Number of proposed tests during the previous month among midwives, nurses and physicians, DOD-CI study, Côte d'Ivoire, $2018(\mathrm{n}=895)$
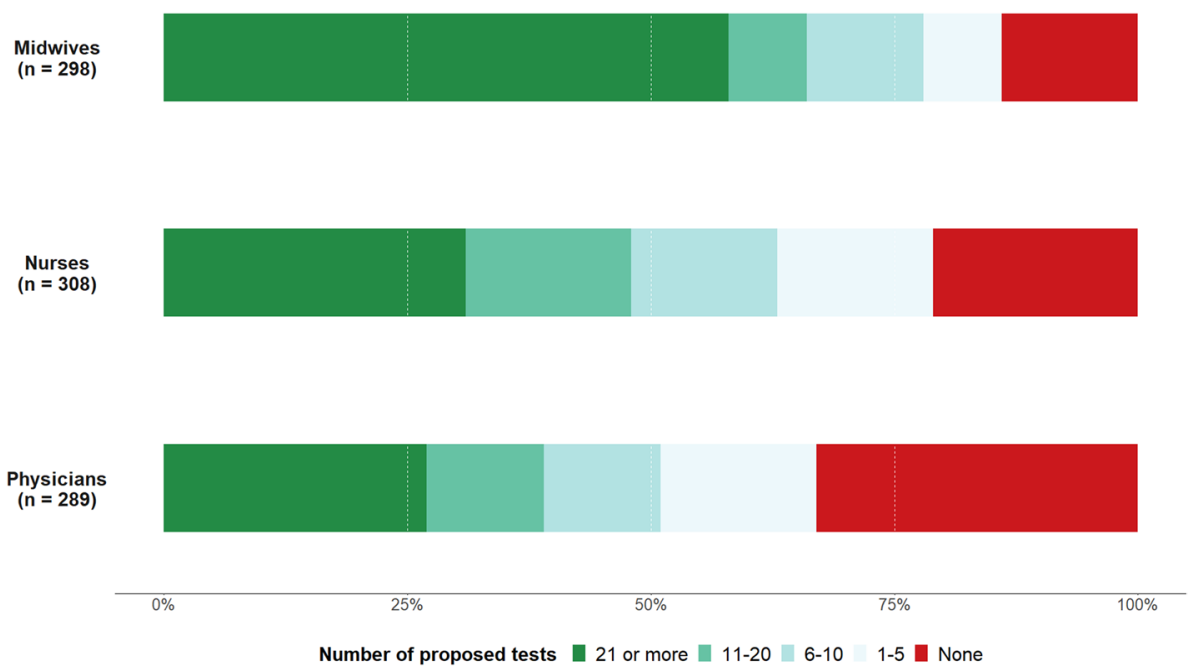


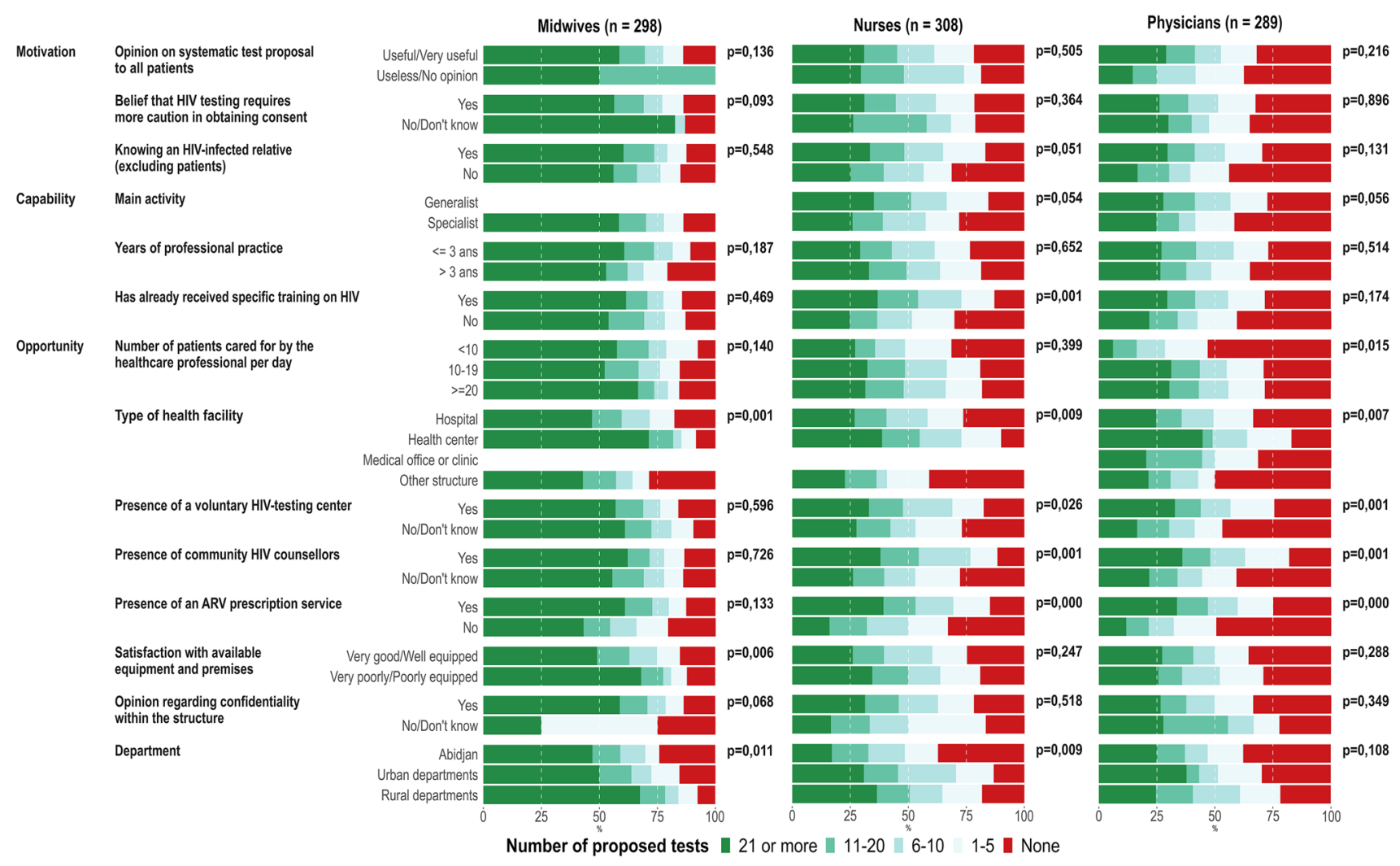

Fig. 3 Factors associated with the number of proposed tests during the previous month among midwives, nurses and physicians, DODCI study, Côte d'Ivoire, $2018(\mathrm{n}=895)$. Midwives and nurses work-

location of the health facility outside Abidjan) were significantly associated with the number of proposed tests (Fig. 4). Having received specific training on HIV and the presence of community HIV counselors in the main facility were associated with a higher number of proposed tests (aOR 2.01 [1.31-3.09], $\mathrm{p}<0.001$ and aOR 1.75 [1.14-2.70], $\mathrm{p}=0.011$, respectively) (Table S3, SDC).

Among physicians, factors related to motivation (knowing a relative living with HIV) and opportunities (type of health facility, number of patients seen per day, presence of a VCT and an ARV prescription service in this facility) were significantly associated with the number of proposed tests (Fig. 4). Knowing a relative living with HIV and the presence of a VTC in the health facility were associated with a higher number of proposed tests (aOR 1.71 [1.01-2.94], $\mathrm{p}=0.048$, and aOR $1.69[1.01-2.86], \mathrm{p}=0.047$, respectively) (Table S3, SDC).

\section{Discussion}

Our results showed different PITC practices depending on the medical profession. Midwives proposed HIV testing more often, followed by nurses and physicians. However, the ing in a medical office or clinic are grouped with the other structures. p-values were computed with Fisher's exact tests

number of proposed tests seemed relatively low compared to the number of patients seen in consultation. In fact, while healthcare professionals reported a median of 15 patients each day, only $39 \%$ reported 21 or more proposed tests during the previous month. The low number of proposed tests seems consistent with other studies conducted in West and Central Africa that show low rates of HIV testing proposal even during recommended events [27-30].The factors associated with PITC practice were also variable according to the medical profession. Environmental opportunities such as the presence of dedicated HIV testing services or dedicated staff increased the number of tests proposed by nurses and physicians. Among midwives, PITC practice was associated with their perception (thinking that HIV testing requires a specific consent procedure). Capability was not associated with PITC practice among physicians and midwives, while for nurses, specific HIV training was strongly associated with a higher number of proposed tests.

Among midwives, the high number of proposed tests suggests routine proposal resulting from their frequent contact with pregnant women for whom a systematic screening test is clearly recommended [31]. Indeed, due to the long history of prevention of mother-to-child transmission programs, midwives are more likely to be informed about this 


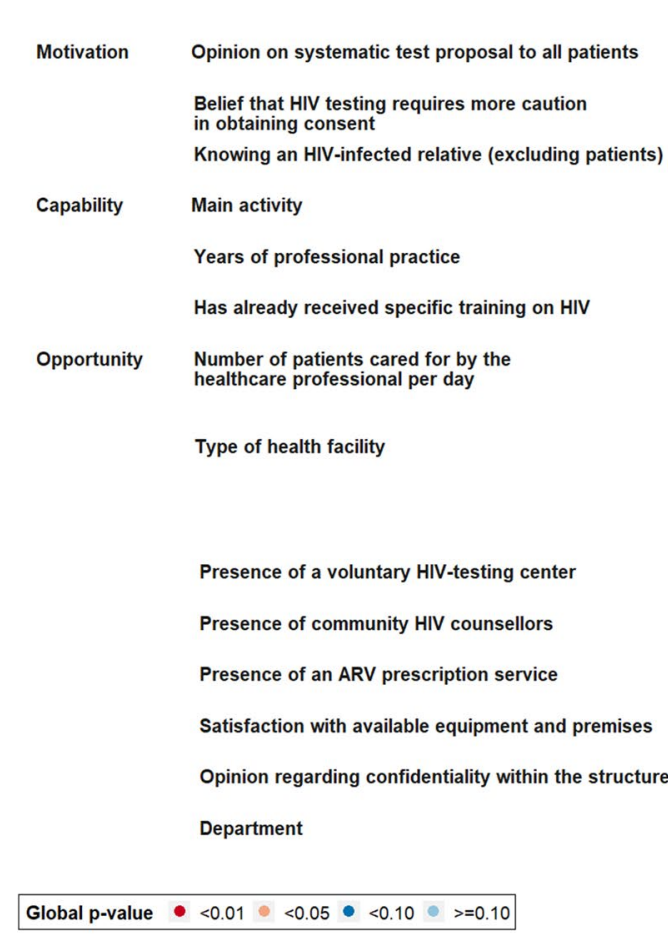

Fig. 4 Ordinal regression model of factors associated with the number of proposed tests during the previous month depending on healthcare professionals' motivations, capabilities and opportunities, by profession, Côte d'Ivoire, DOD-CI study, $2018(\mathrm{n}=895)$. Midwives

recommendation and to have learned it during their basic training. This could explain the lesser influence of their capabilities and of environmental opportunities on their PITC practice because PITC is an integral part of their current practice. PITC practice among midwives seemed to be related to their perceptions: the $8 \%$ of those who did not perceive the need to obtain specific consent for HIV testing were more likely to propose a higher number of tests. However, it is difficult to know whether the perception of specific consent influences midwives' PITC practice or whether the practice of routine PITC changes midwives' perceptions about obtaining consent. Other studies have noted difficulties in obtaining consent and therefore difficulty in proposing the test as barriers to PITC $[8,9,12]$. Simplifying consent collection and standardizing PITC in everyday medical practice should facilitate routine PITC practice.

Whereas PITC was seen as an integral part of midwives' work, physicians and nurses perceived PITC as a 'separate activity' requiring dedicated staff, training and funding [22]. This could explain the lower number of proposed tests by nurses and physicians as well as the positive association between this number and specific HIV training (for nurses) and the presence of staff or places dedicated to HIV testing (for both nurses and physicians). and nurses working in a medical office or clinic are grouped with the other structures. Likelihood ratio tests were used to calculate the global p-values

Additionally, the less frequent practice of PITC among nurses and physicians could result from unclear national recommendations in Côte d'Ivoire, which stipulate a routine testing proposal to any person seen in consultation while drawing a somewhat 'broad' prioritization for certain audiences [31]:

Since Côte d'Ivoire is a country with a mixed HIV epidemic, HIV testing services must be available to all people, regardless of age and socio-professional group. However, the availability of testing services will be increased in high-prevalence areas and for vulnerable populations most at risk of HIV infection. These vulnerable populations, priority targets for screening, are: symptomatic patients (suggestive signs of HIV infection, signs of malnutrition, signs of sexually transmitted infection, signs of tuberculosis), sex workers and their stable partners, men who have sex with men, truck drivers, prison populations, drug users including injectable drug users, men in uniform, migrants, truck drivers, orphans and vulnerable children, children born from HIV-positive mothers, pregnant women and their spouses, adolescents and young girls, persons aged 40 and over and family members of index subjects' 
International donors such as PEPFAR (which funds $77 \%$ of the fight against HIV in Côte d'Ivoire) have a stronger targeting strategy [32]. These discrepancies between the strategies of political decision makers and donors could explain the lesser involvement of nurses and physicians in routine PITC. In practice, physicians and nurses carry out PITC in a targeted manner, mainly based on clinical criteria [22].

The nonsystematic and autonomous PITC practice among physicians and nurses may explain the greater number of factors associated with PITC practice compared to midwives. However, these factors differed between nurses and physicians.

Nurses' capabilities, including having received HIV training, appeared to be related to the number of proposed tests, which was not the case for other professionals. Other data from our study showed that $20.8 \%$ of nurses reported difficulties in offering testing that were mainly related to the patient-caregiver relationship (e.g., reluctance to propose the test to certain audiences, fear of reporting a positive result, fear of having their testing proposal rejected; results not presented). These difficulties, which are related to counseling management, were also documented in other African contexts [8-12]. HIV-specific training would make it easier for nurses to address the issue of testing their patients, especially since only half of nurses have already received specific training related to HIV.

Among physicians, PITC practice was related to their motivation or perceptions more than to their capability. This difference could be explained by the greater autonomy of physicians in their professional practice. Physicians practice PITC when they are personally sensitized to it (e.g., by knowing a relative living with HIV), while nurses practice it when they are professionally sensitized (e.g., dedicated HIV training). A study conducted in Côte d'Ivoire in 2014 showed that physicians had a lack of interest and motivation in the practice of PITC, which underlines the importance of physicians' motivations in their PITC practice [22].

The environmental opportunities, including the model of PITC organization, were linked to the practice of PITC among both nurses and physicians. The presence of community HIV counselors and/or a voluntary testing center seemed to increase the number of proposed tests. Healthcare professionals may be more inclined to offer HIV testing when it is not necessary for them to perform all the testing steps (i.e., counseling, blood sampling, and result announcement), which they may consider time-consuming or not part of their work [18, 22].

Some environmental opportunities linked to PITC practice were common to all professionals. The absence of an ARV prescription service was an obstacle to PITC for all healthcare professionals. The inability to deliver ARV treatment onsite following a positive result could create reluctance among healthcare professionals to initiate PITC.
In theory, the number of proposed tests should increase with the number of patients seen in consultation, although this was not the case for midwives and nurses. It is possible that managing a large number of patients, and therefore a higher workload, leaves less time to practice PITC. Studies tend to show that an overcrowded environment that involves many patients and long queues can force professionals to not offer the test due to a lack of time or insufficient staff [8-16].

Our study had some limitations, including memory bias that may have underestimated the number of proposed tests in consultation. However, the fact that the number of tests was limited to those proposed in the month preceding the survey may have reduced this bias. Reporting bias including desirability or uncoordinated responses between practice and reporting may have occurred since data were based on individual statement. To limit the impact of this effect, we have reassured participants that the study was anonymous and that no personal information was shared. In addition, we collected the number of proposed tests and the number of patients seen in consultation directly per interval at the time of collection; thus, we could not calculate test proposal rates (i.e., the ratio of the number of proposed tests to the number of patients seen in consultation).

Physician participation rates were lower than the rates for other health professionals but remained comparable to or higher than those in other studies conducted among physicians in this context [33, 34]. In addition, the distribution by sex and region of the different professionals in our sample was similar to the data in the annual report on the health situation in Côte d'Ivoire [35]. Our three samples of health professionals are therefore representative of their respective populations on a national scale.

The targeted practice of PITC among physicians and nurses raises the question of their ability to identify the most exposed audiences. Some populations are at risk because of their sexual behavior (e.g., multiple sexual partners, sex between men, commercial sex), yet their identification by healthcare professionals is often difficult because patients do not spontaneously communicate about their sexual practices, and health professionals do not routinely assess the risks of their patients [36, 37]. Given the trend toward targeted use of the PITC in both national policies and healthcare professional practice, clearly stated targeting modalities (e.g., the public concerned, modality for risk assessment for patients) seem necessary to avoid missing testing occasions for undiagnosed HIV patients.

\section{Conclusion}

Although environment opportunities (such as dedicated staff or services) had an influence on PITC, capabilities and motivations had an effect of HIV testing proposals, but this effect differed by medical profession. 
For midwives, routine integration of the HIV testing proposal as part of standard care appeared to be a key element for systematic HIV testing. However, there are remaining gaps, and the consent process could be simplified and aligned with other screening processes.

For nurses, improving their capabilities, particularly dedicated HIV testing training, can lead to better testing.

For physicians, motivations and perceptions are linked to their PITC practice, suggesting the need for actions to raise their awareness of PITC and clearer recommendations on when to test.

Acknowledgements We would like to thank the healthcare workers who agreed to participate to the survey as well as the implementing partners and other stakeholders who supported the deployment of the survey. ANRS 12323 DOD-CI Study Group: Côte d'Ivoire: Nelly ASSOUMOU (PAC-CI), Anne BEKELYNCK (PAC-CI), Christine DANEL (PAC-CI), Mohamed DOUMBIA (Institut d'Ethnosociologie), Mariatou KONE (Institut d'Ethnosociologie), Alexis KOUADIO (Institut d'Ethnosociologie), Arsène Kra Kouassi (PAC-CI), Serge NIANGORAN (PAC-CI), Honoré OUANTCHI (Institut d'Ethnosociologie), Lazare SIKA (ENSEA). France: Séverine CARILLON (Ceped), Maxime INGHELS (Ceped), Joseph LARMARANGE (IRD, Ceped).

Author contributions ML, conceptualization, data curation, formal analysis, methodology, validation, visualization, writing of original draft, review and editing of final draft; $\mathrm{AKK}$ and $\mathrm{SN}$, data curation, formal analysis and project administration; $\mathrm{AB}$ and $\mathrm{SC}$, conceptualization, methodology, project administration, review and editing of final draft; LS, CD, MK, ADL, JL, conceptualization, methodology, review and editing of final draft.

Funding The study was funded by the France Recherche Nord \& Sud Sida-HIV Hépatites (https://www.anrs.fr, Grant Number: ANRS 12,323). Maxime INGHELS received a grant from the association SIDACTION as part of his $\mathrm{PhD}$ work. The funders had no role in study design, data collection and analysis, decision to publish, or preparation of the manuscript.

Data availability Data protection, confidentiality and privacy Data has been anonymized; All identifying data (e.g. telephone numbers) have been deleted.

\section{Compliance with ethical standards}

Conflict of interest The authors declare that they have no conflict of interest.

Ethical Approval All procedures performed in the study were in accordance with the ethical standards of the National Research Ethics Committee of Côte d'Ivoire (N/Ref: 058/MSHP/CNER-kp) and with the 1964 Helsinki declaration and its later amendments or comparable ethical standards.

Informed Consent Informed consent was obtained from all individual participants included in the study.

Open Access This article is licensed under a Creative Commons Attribution 4.0 International License, which permits use, sharing, adaptation, distribution and reproduction in any medium or format, as long as you give appropriate credit to the original author(s) and the source, provide a link to the Creative Commons licence, and indicate if changes were made. The images or other third party material in this article are included in the article's Creative Commons licence, unless indicated otherwise in a credit line to the material. If material is not included in the article's Creative Commons licence and your intended use is not permitted by statutory regulation or exceeds the permitted use, you will need to obtain permission directly from the copyright holder. To view a copy of this licence, visit http://creativecommons.org/licenses/by/4.0/.

\section{References}

1. WHO, Unaids. Guidance on provider-initiated HIV testing and counselling in health facilities. Geneva: World Health Organization; 2007.

2. Baggaley R, Hensen B, Ajose O, et al. From caution to urgency: the evolution of HIV testing and counselling in Africa. Bull World Health Organ. 2012;90(9):652-8.

3. Kennedy CE, Fonner VA, Sweat MD, Okero FA, Baggaley R, O'Reilly KR. Provider-initiated HIV testing and counseling in low- and middle-income countries: a systematic review. AIDS Behav. 2013;17(5):1571-90.

4. Hensen B, Baggaley R, Wong VJ, et al. Universal voluntary HIV testing in antenatal care settings: a review of the contribution of provider-initiated testing \& counselling. Trop Med Int Health TM IH. 2012;17(1):59-70.

5. Roura M, Watson-Jones D, Kahawita TM, Ferguson L, Ross DA. Provider-initiated testing and counselling programmes in subSaharan Africa: a systematic review of their operational implementation. AIDS. 2013;27(4):617-26.

6. Kapologwe NA, Kabengula JS, Msuya SE. Perceived barriers and attitudes of health care providers towards provider-initiated HIV testing and counseling in Mbeya region, southern highland zone of Tanzania. Pan Afr Med J. 2011;8:17.

7. Davyduke T, Pietersen I, Lowrance D, Amwaama S, Taegtmeyer M. Opportunities for strengthening provider-initiated testing and counselling for HIV in Namibia. AIDS Care. 2015;27(8):990-4.

8. Ahmed S, Bärnighausen T, Daniels N, Marlink R, Roberts MJ. How providers influence the implementation of provider-initiated HIV testing and counseling in Botswana: a qualitative study. Implement Sci IS. 2016;11:18.

9. Evans $\mathrm{C}$, Ndirangu E. Implementing routine provider-initiated HIV testing in public health care facilities in Kenya: a qualitative descriptive study of nurses' experiences. AIDS Care. 2011;23(10):1291-7.

10. Rogers AJ, Weke E, Kwena Z, et al. Implementation of repeat HIV testing during pregnancy in Kenya: a qualitative study. BMC Pregnancy Childbirth. 2016;16(1):151.

11. Medley AM, Kennedy CE. Provider challenges in implementing antenatal provider-initiated HIV testing and counseling programs in Uganda. AIDS Education. 2010;22(2):87-99.

12. Pope DS, Atkins S, DeLuca AN, et al. South African TB nurses' experiences of provider-initiated HIV counseling and testing in the Eastern Cape Province: a qualitative study. AIDS Care. 2010;22(2):238-45.

13. Sibanda EL, Hatzold K, Mugurungi O, et al. An assessment of the Zimbabwe ministry of health and child welfare provider initiated HIV testing and counselling programme. BMC Health Serv Res. 2012;12:131.

14. Kiene SM, Sileo K, Wanyenze RK, et al. Barriers to and acceptability of provider-initiated HIV testing and counselling and adopting HIV-prevention behaviours in rural Uganda: a qualitative study. J Health Psychol. 2015;20(2):173-87. 
15. Leon N, Lewin S, Mathews C. Implementing a provider-initiated testing and counselling (PITC) intervention in Cape town, South Africa: a process evaluation using the normalisation process model. Implement Sci IS. 2013;8:97.

16. Plotkin M, Besana GVR, Yuma S, et al. Integrating HIV testing into cervical cancer screening in Tanzania: an analysis of routine service delivery statistics. BMC Womens Health. 2014;14:120.

17. Sarker M, Papy J, Traore S, Neuhann F. Insights on hiv pretest counseling following scaling-up of PMTCT program in rural health posts, Burkina Faso. East Afr J Public Health. 2009;6(3):280-6.

18. McNaghten AD, Schilsky Mneimneh A, Farirai T, et al. Implementation and operational research: strengthening HIV test access and treatment uptake study (Project STATUS): a randomized trial of HIV testing and counseling interventions. J Acquir Immune Defic Syndr. 2015;70(4):e140-146.

19. Inghels M, Carillon S, Desgrees du Lou A, Larmarange J. Effect of organizational models of provider-initiated testing and counseling (PITC) in health facilities on adult HIV testing coverage in sub-Saharan Africa. AIDS Care. 2020;32(2):163-9.

20. Ministère de la Santé et de l'Hygiène Publique [Côte d'Ivoire]. Document de Politique, Normes et Procedures des Services de dépistage du VIH en Côte d'Ivoire, édition 2014. Abidjan : Ministère de la santé; 2014.

21. Ministère de la santé et de l'hygiène publique [Côte d'Ivoire]. Rapport Annuel sur la Situation Sanitaire 2017. Abidjan : Ministère de la santé; 2018.

22. Carillon S, Bekelynck A, Assoumou N, et al. "Il y a des conseillers communautaires payés pour ça ! » Les réticences des soignants à la proposition systématique d'un test VIH en consultation de médecine générale. Le Cas de la Côte d'Ivoire. Abidjan: presented at the International Conference on AIDS and STIs in Africa (ICASA) 2017; 2017 Poster THPDD255, Volet D, Thursday 7 th.

23. UNAIDS. Data 2018. UNAIDS : Geneva; 2018. https://www.unaid s.org/sites/default/files/media_asset/unaids-data-2018 en.pdf

24. UNAIDS. Knowledge is power. UNAIDS : Geneva; 2018 p. 32.

25. Boudreau J, Hopp W, McClain JO, Thomas LJ. On the interface between operations and human resources management. Manuf Serv Oper Manag. 2003;5(3):179-202.

26. Christensen RHB. Ordinal: Regression Models for Ordinal Data. 2019. https://CRAN.R-project.org/package=ordinal

27. Yotebieng M, Wenzi LK, Basaki E, et al. Provider-Initiated HIV testing and counseling among patients with presumptive tuberculosis in Democratic Republic of Congo. Pan Afr Med J. 2016;25:161.

28. Nyuzaghl J, Ohene S, Odoi-Agyarko K. Acceptability of routine offer of HIV Testing (opt-out approach) among pregnant women in the Wa municipality. Ghana Med J. 2011;45(1):10-5.

29. Hembah-Hilekaan SK, Swende TZ, Bito TT. Knowledge, attitudes and barriers towards prevention of mother-to-child transmission of HIV among women attending antenatal clinics in Uyam District of Zaki-Biam in Benue State. Nigeria Afr J Reprod Health. 2012;16(3):28-35.

30. Inghels M, Kouassi AK, Niangoran S, et al. Cascade of Provider-Initiated Human Immunodeficiency Virus Testing and Counselling at Specific Life Events (Pregnancy, Sexually Transmitted Infections, Marriage) in Côte d'Ivoire. Sex Transm Dis. 2020;47(1):54-61.

31. Programme National de Lutte contre le SIDA [Côte d'Ivoire]. Document de Politique, Normes et Procédures des Services de dépistage du VIH en Côte d'Ivoire, Edition 2016. Abidjan : Ministère de la santé; 2016.

32. PEPFAR. Côte d'Ivoire, Country Operational Plan (COP) 2018, Strategic Direction Summary; 2018.

33. Boby B, Ouattara ND, Guessennd N, Gbonon V, Guinan JC, Dosso M. Utilisation de l'enquête téléphonique comme outil de collecte d'information dans un pays en voie de développement : cas de la prise en charge des infections urinaires non compliquées en Côte d'Ivoire en. Cah Santé Publique. 2012;2012:48-55.

34. Cull WL, O'Connor KG, Sharp S, Tang SS. Response rates and response bias for 50 surveys of pediatricians. Health Serv Res. 2005;40(1):213-26.

35. Ministère de la santé et de l'hygiène publique [Côte d'Ivoire]. Rapport Annuel sur la Situation Sanitaire 2016. Abidjan : Ministère de la santé; 2017.

36. Champenois K, Cousien A, Cuzin L, et al. Missed opportunities for HIV testing in newly-HIV-diagnosed patients, a cross sectional study. BMC Infect Dis. 2013;13:200.

37. Inghels M, Niangoran S, Minga A, et al. Missed opportunities for HIV testing among newly diagnosed HIV-infected adults in Abidjan, Côte d'Ivoire. PLoS ONE. 2017;12(10):e0185117.

Publisher's Note Springer Nature remains neutral with regard to jurisdictional claims in published maps and institutional affiliations. 